\title{
CSF 5-HIAA and Nighttime Activity in Free-Ranging Primates
}

\author{
P.T. Mehlman, Ph.D., G.C. Westergaard, Ph.D., B.J. Hoos, B.A., F.R. Sallee, M.D., Ph.D., \\ S. Marsh, S.J. Suomi, Ph.D., M. Linnoila, Ph.D., and J.D. Higley, Ph.D.
}

Men with low CNS serotonin turnover, as measured by cerebrospinal fluid 5-hydroxyindoleacetic acid (CSF 5-HIAA) concentrations, exhibit aberrant circadian activity patterns characterized by disrupted sleep rhythms and daytime hyperactivity. To assess whether similar patterns are found in nonhuman primates we examined the relationship between CSF 5-HIAA and nighttime activity in free-ranging monkeys. CSF samples were obtained from 16 adult male rhesus macaques living on a 475 acre, heavily forested sea island. Each subject was captured, fitted with a radio-telemetry motion-detector collar, and then released back into its group. A receiver placed near the sleeping trees of the study subjects recorded activity between $2100 \mathrm{hrs}$ and 0600 hrs. Trained observers recorded behavioral data during the day. The animals followed a typical diurnal activity pattern, as they were active $74 \%$ of the sampled time during the day and $37 \%$ of the sampled time during the night. CSF 5-HIAA concentrations were inversely correlated with total duration of nighttime activity as well as mean duration of all active events. Nighttime activity was inversely correlated with daytime activity. CSF 3-methoxy-hydroxyphenylglycol (MHPG) concentrations were positively correlated with total nighttime activity, and inversely correlated with daytime sleep frequency. We conclude that male rhesus with low CSF 5-HIAA concentrations have higher total nighttime activity, longer mean periods of nighttime activity, and sleep more during the day than do males with high CSF 5-HIAA concentrations. This suggests that low serotonergic neurotransmission is associated with aberrant diurnal activity, as evidenced by a disruption of nighttime sleep patterns and a compensatory higher rate of inactivity during the day. [Neuropsychopharmacology 22: 210-218, 2000] Published by

Elsevier Science Inc.
From the Division of Research and Development (GCW, BJH), LABS of Virginia, Inc., Yemassee, SC; Laboratory of Comparative Ethology (GCW, SJS), National Institute of Child Health and Human Development, Polesville, MD; Laboratory of Clinical Studies (PTM, ML, JDH), National Institute on Alcohol Abuse and Alcoholism, Bethesda, MD; Medical University of South Carolina, Department of Psychiatry and Behavioral Science (FRS), Charleston, SC; Tao-Tech, Inc. (SM), Bedford, MA.

Address correspondence to: Dr. G.C. Westergaard, Head, Division of Research, LABS of Virginia, Inc., P.O. Box 557, Yemassee, SC 29945.

Received February 12, 1999; revised June 16, 1999; accepted August 20, 1999.

Dr. P.T. Mehlman and Dr. G.C. Westergaard are to be considered as co-first authors whose names are interchangeable. Dr. Mehlman was the Principal Investigator when the study was designed, the data were collected and analyzed, and was the first author when
KEY WORDS: Sleep, serotonin, impulsivity, primate, aggression

Psychiatric research suggests that a reduced turnover rate of serotonin in the central nervous system (CNS), as measured by cerebrospinal fluid (CSF) 5-hydroxyindoleacetic acid (5-HIAA), is a risk factor for impaired impulse control, violent behavior, and premature mortality from suicide and violence (Faustman et al. 1990; Kruesi et al. 1990; Lidberg et al. 1985; Linnoila et al.

this manuscript was originally submitted. Dr. Westergaard was the Principal Investigator when the manuscript was revised and resubmitted for publication in this journal. 
1983; Virkkunen et al. 1994). Research using nonhuman primates has replicated and extended many of these findings (Higley et al. 1996a; Higley et al. 1992a; Higley et al. 1996b; Kaplan et al. 1994; Mehlman et al. 1995; Mehlman et al. 1994; Mehlman et al. 1997; Raleigh 1987; Raleigh et al. 1983a; Raleigh et al. 1983b; Raleigh et al. 1980; Raleigh and McGuire 1994). Further, this research has demonstrated that inter-individual differences in CSF 5-HIAA concentrations are stable across time and experimental settings and can be attributed to genetic and early environmental influences that produce lasting modifications in the CNS serotonin response (Higley et al. 1996b; Higley et al. 1994; Higley et al. 1996a).

Serotonin-mediated behavioral deficits are thought to result in part from an inability to maintain a homeostatic response in a number of physiological systems (Virkkunen et al. 1989a; Virkkunen and Narvanen 1987; Virkkunen et al. 1994). Various lines of evidence indicate that central serotonin neurotransmission contributes to regulation of sleep-wake cycles and circadian activity patterns. For example, several decades of research has shown that the sleep-wake cycle is partially modulated by serotonin release from projections of the ralphe nuclei (Jacobs 1991; Jouvet 1974; Jouvet 1967; Koella 1985; Koella and Czicman 1966; Maeda et al. 1989; Puizillout et al. 1981). Further, administration of p-chlorophenylalanine (PCPA), which inhibits the synthesis of serotonin, causes a reduction in total sleep in the cat (Jouvet 1974), rat (Torda 1967), and monkey (Weitzman et al. 1968). Finally, experimentally induced lesions of the ralphe system lead to nerve terminal decreases in 5-HT and 5-HIAA which are directly proportional to the degree of insomnia produced by the lesions (Jouvet 1974). These findings support the view that increases in CNS serotonin turnover rate promote sleep, in particular NREM sleep, and that deficits in serotonergic transmission are associated with insomnia, high levels of nighttime activity and/or other sleep disturbances (Jouvet 1974; Koella 1985).

Recent evidence from studies of rodents also highlights the role of serotonin in modulating circadian activity patterns through serotonergic projections to the endogenous circadian pacemaker (Klein et al. 1991; Miller et al. 1996), the suprachiasmatic nucleus (MeyerBernstein et al. 1997; Meyer-Bernstein and Morin 1996). For example, 5-HT is believed to regulate the phasic effects of light on circadian rhythms (Kennaway et al. 1996; Meyer-Bernstein and Morin 1996; Prosser et al. 1993; Selim et al. 1993; Smale et al. 1990). Also, fluoxetine-induced increases in serotonergic transmission decrease the duration of circadian periods (Possidente et al. 1996), and serotonergic afferents to the suprachiasmatic nucleus are necessary to synchronize nonphotic activity cues into circadian patterns (Edgar et al. 1997). These findings suggest that a reduced central serotonin turnover rate may be conducive to disruptions in circa- dian patterns of activity, and that these disruptions may lead to increased rates of nighttime activity and/or concomitant sleep disturbances.

Few human studies have directly investigated the relationship between impaired CNS serotonin turnover rate and aberrant diurnal sleep-wake cycles. However, in a recent study of male alcoholic offenders, Virkkunen and colleagues (Virkkunen et al. 1994) found that offenders grouped by antisocial personality disorder (ASP) and intermittent explosive disorder (IED) have low CSF 5-HIAA concentrations and exhibit higher levels of nighttime activity than do healthy volunteers. However, ASP offenders exhibit higher levels of daytime activity than do healthy volunteers, pointing to a general disruption of diurnal activity patterns. In contrast, IED offenders show levels of daytime activity that cannot be distinguished from those of normal controls. A recent laboratory study suggested that a similar relationship between impaired CNS serotonin and aberrant circadian activity may also exist in nonhuman primates, as socially housed juvenile and adolescent macaques with low CSF 5-HIAA concentrations failed to fall asleep readily and were more likely to exhibit excessive activity during the daytime hours than were macaques with high CSF 5-HIAA concentrations (Zajicek et al. 1997). However, in this study 24-hour assessments were not made and the high number of monkeys that were confined together in a cage may have confounded the results.

In the present study we investigated the relationship between nighttime activity and CSF 5-HIAA concentrations in free ranging rhesus macaques (Macaca mulatta). Rhesus macaques are well suited for making such assessments because CSF can be removed from the cisterna magna, where measurements of 5-HIAA probably better reflect CNS serotonin activity than do lumbar punctures. Studies show that while serotonin turnover is relatively rapid, 5-HIAA concentrations are more slowly changing, requiring 30 minutes or longer to reflect the upstream changes (Bacopoulos et al. 1979; Brammer et al. 1987; Higley et al. 1991), thus allowing one to assess naturally occurring serotonin activity of a subject. As noted, this assessment shows that subjects exhibit unique and stable interindividual differences that persist across time and setting (Higley et al. 1996a; Higley et al. 1994; Higley et al. 1996b). A natural setting provides a unique opportunity for studying nighttime activity, which is highly influenced by social and environmental factors. For example, monkeys at our study site find a new sleep area in their home range each night, and enter sleeping trees up to $15 \mathrm{~m}$ in height before sunset and remain until daybreak. These conditions are quite different than those found in standard laboratory settings where animals may be singly caged and subject to unnatural disturbances from laboratory personnel and colony management practices. Based on 
animal and human studies showing a relationship among serotonin, total sleep duration, and circadian activity patterns, we tested the hypothesis that rhesus macaques with low CSF 5-HIAA concentrations show higher levels of nighttime activity than do rhesus macaques with high CSF 5-HIAA concentrations. Second, we evaluated whether subjects with high levels of nighttime activity and low concentrations of CSF 5HIAA have daytime activity patterns that more closely resemble human offenders diagnosed with antisocial personality disorder (ASP) or intermitent explosive disorder (IED).

\section{METHOD}

\section{Subjects}

The subjects were 16 adult male rhesus macaques with a mean age of 86 months at the onset of this study. The animals are part of a free-ranging colony of approximately 4500 monkeys that reside on a 475 -acre South Carolina sea island. At the time of sampling the population was organized into 35 social groups with an adult sex ratio of 2.5 females to 1 male. Subjects were selected when they were juveniles, 18-24 months of age. To assure a normative sample of CSF 5-HIAA and aggressive subjects, eight of the subjects in the pre-established age range were selected on a random basis. Four more were selected on the basis of observations of aggressive behavior in the corral and/or by their fight wounds, and the remaining four were selected on the basis of their display of submissive and/or fear-related behaviors in the corral. Preliminary assessments of CSF 5-HIAA concentrations showed that these subjects were representative of the overall population sample. More details on the study population can be found in previous publications (Higley et al. 1992a,b; Higley et al. 1996b; Higley et al. 1996c; Mehlman et al. 1995; Mehlman et al. 1994; Mehlman et al. 1997; Taub and Mehlman 1989).

\section{Methods of Capture}

We trapped animals by concealing technicians in blinds near the entrances of ten capture corrals. Corn, fruit, and commercial monkey chow were placed in the corral, and as each subject entered the corral to forage a technician closed the door. The animal was then netted, anesthetized (ketamine hydrochloride, $10 \mathrm{mg} / \mathrm{kg}$, IM), and driven to a clinic area where a CSF sample was obtained. After the CSF sample was obtained, the animal was weighed, given a physical examination, and fitted with a motion sensing radio telemetry transmitter. Upon full recovery from anesthesia, the animal was released near its social group.

\section{Physiological Data Collection}

Physiological samples were obtained between 0900 and $1600 \mathrm{hrs}$ over a four-day period. We used a 22-gauge needle and a $5 \mathrm{cc}$ syringe to obtain 3-ml CSF samples from the cisterna magna of each male within 35 minutes of ketamine injection. Previous studies have shown that there is no significant capture effect on CSF monoamine concentrations if samples are obtained within 30 to 35 minutes of ketamine injection (Bacopoulos et al. 1979; Brammer et al. 1987; Higley et al. 1991). As in our earlier study (Higley et al. 1991), preliminary analyses indicated that neither time to capture nor time from ketamine injection to the CSF sample was correlated with monoamine concentrations. The samples were quick frozen on dry ice, stored at $-70^{\circ}$, and later assayed for 5-HIAA, homovanillic acid (HVA), and 3-methoxyhydroxyphenylglycol (MHPG) using high performance liquid chromatography with electrochemical detection (Scheinin et al. 1983). All intra and interassay coefficients of variation were less than $10 \%$ (Higley et al. 1992a,b; Mehlman et al. 1995; Mehlman et al. 1994).

\section{Nighttime Behavioral Data Collection}

Each radio telemetry collar contained a motion detector that altered the rate of signal emission depending on the orientation and change in orientation of the radio transmitter. These signals were monitored with a radio telemetry receiver and fed into an electronic activity recorder (MPC-100) that averaged these signals over 10-sec intervals. The numerical output of the EAR was loaded into a commercial database program so that each subject's nighttime activity output could be graphically represented as mean milliseconds per 10-sec interval. Periods of flat output or only very small oscillations were scored as inactive periods, alternating with active periods. Spikes of activity within each flat-line output were counted as activity if they exceeded 20 seconds in duration. Activity was thus measured as frequency (number of periods per sample), duration (number of total minutes spent in activity and inactivity), and a derived variable, the mean length of activity periods, created by dividing total duration by the frequency of active periods. Before beginning the formal phase of the study, the collars were tested on single-caged and group housed males. Behavioral observations showed a high degree of correspondence between data collected with using direct observations and data collected using the motion detectors.

Nighttime data collection occurred over a 45-day period that began within 30 days after physiological data had been collected. A technician located each subject between 1930 and $2030 \mathrm{hrs}$ and settled in near the sleeping site to allow the group time to habituate to the technician's presence. The MPC-100 was used to collect 
nighttime data. Recording sessions began at 2100 hours. The MPC-100 collected and stored data for two periods of five and four hours each, representing the time between $2100 \mathrm{hrs}$ each night and $0600 \mathrm{hrs}$ the next morning. During the study we discovered that one subject had received a severe wound as the result of inter-male aggression. His nighttime and daytime behavior was biased towards inactivity (presumably because his wound was healing). As a result we omitted these data from further consideration.

\section{Accuracy of the Electronic Nighttime Recordings}

Laboratory tests taken prior to field use showed the MPC-100 to be sensitive enough to detect subtle body movements, but less sensitive to movements that were limited to head-only or leg-only movements that did not involve changes in body posture. To verify the relationship between activity periods measured by the MPC-100 and real-time patterns of activity, we collected simultaneous sampling using the MPC-100 and a field observer for a 16-minute period for each individual. During this time, the observer recorded all frequencies and durations of lying and sitting without significant head movement. The majority of the inactive periods were spent in trees $(85 \%)$ and consisted of the animal sitting or lying quietly. The observations of lying and quiet sitting were thus pooled together to represent periods of inactivity, measured by frequency and total duration. Activity periods were derived from these data, as well as mean duration of active periods, and we then correlated the MPC-100 output with the simultaneous field observations. For duration and frequency data there were significant positive correlations between the two methods (for duration data, $r(13)=.68, p=.004$; for frequency data, $r(13)=.52, p=.04)$.

\section{Daytime Behavioral Data Collection}

Daytime behavioral data collection occurred over a 45day period that began with the onset of nighttime data collection. We collected daytime data using focal animal sampling randomized for subject order and representational by time of day. A total of 70 hours of observations were made during ten sessions. All subjects were followed in the field with radio telemetry. Quantitative behavioral data were collected on frequency and duration of lying or sleeping, and the behaviors were combined to represent periods of inactivity. Non-sleeping data were found to be heterogeneous with respect to the simultaneous occurrence of foraging, grooming, head movements, etc. Duration and frequency of daytime activity were then calculated from the frequency and duration of inactivity data. Observations were also collected on frequencies of yawning. An event was considered to have ended if it stopped and did not resume within 10 seconds. Both observers were blind to the physiological data and the hypotheses being tested. To establish inter-observer reliability, simultaneous observation sessions were conducted at the beginning, midpoint, and end of the study. During these sessions, both observers scored the same subjects for concurrent 15minute periods. All inter-observer reliabilities on the various categories of behavior were determined by Cohen's kappa test values to be greater than 0.85 .

\section{Preliminary Data Analyses}

All correlation coefficients reported herein are Pearson product-moment with an alpha level of 0.05 . We partialled out subject age and weight by use of standardized residuals for physiological variables affected by these potential confounding variables. Measures related to conditions of capture (time of day, elapsed time between capture and sampling, etc.), as well as age and weight, were then correlated with physiological measures to determine whether these factors could be considered confounds. Time of Day and Time to CSF were not significantly correlated with CSF metabolite levels. As expected, weight and age were positively correlated with each other $(r(13)=.53, p<.04)$, and with CSF 5-HIAA $(r(13)=-.58$ and -.68 , respectively, $p<.03)$ and HVA $(r(13)=-.72$ and -.55 , respectively, $p<.04)$.

\section{RESULTS}

\section{Physiological Measures}

The mean CSF 5-HIAA concentration per subject was $152 \mathrm{pmols} / \mathrm{ml}$ (range $=98-226 \mathrm{pmols} / \mathrm{ml}$; s.d. $=42$ pmols $/ \mathrm{ml}$ ). The mean CSF HVA concentration per subject was $760 \mathrm{pmols} / \mathrm{ml}$ (range $=465-1394 \mathrm{pmols} / \mathrm{ml}$; s.d. $=223$ pmols $/ \mathrm{ml}$ ). The mean CSF MHPH concentration per subject was $129 \mathrm{pmols} / \mathrm{ml}$ (range $=68-159$ pmols $/ \mathrm{ml}$; s.d. $=27$ pmols $/ \mathrm{ml}$ ). We noted significant positive correlations between CSF 5-HIAA and HVA concentrations $(r(13)=.63, p<.01)$. We noted a significant negative correlation between CSF MHPG and HVA $(r(13)=-.52, p<.05)$. The correlation between CSF MHPG and 5-HIAA was not statistically significant $(r(13)=-.07)$.

\section{Nighttime Activity}

The relationships between the three measures of nighttime activity are displayed in Table 1 . Total duration of nighttime activity was positively correlated with mean duration of nighttime activity $(r(13)=.72, p<.002)$, as was frequency and total duration of nighttime activity $(r(13)=.53, p<.04)$. We noted an inverse correlation between total duration and frequency of nighttime inactivity periods $(r(13)=-.53, p<.04)$ indicating that as 
Table 1. Descriptive Statistics for Nighttime Activity Measures and Pearson $r$ Correlations Between the Three Measures. For all Measures $n=15$.

\begin{tabular}{|c|c|c|c|c|c|c|}
\hline \multirow[b]{3}{*}{ EAR measures } & \multirow{2}{*}{\multicolumn{4}{|c|}{ Descriptive Statistics }} & \multicolumn{2}{|c|}{ Correlations } \\
\hline & & & & & \multirow{2}{*}{$\begin{array}{c}\text { Total } \\
\text { Duration }\end{array}$} & \multirow{2}{*}{$\begin{array}{c}\text { Mean } \\
\text { Duration }\end{array}$} \\
\hline & mean & s.d. & low & high & & \\
\hline Frequency Activity & 20.0 & 9.8 & 4 & 36 & $r=.53^{*}$ & \\
\hline \multicolumn{7}{|l|}{ Total Duration } \\
\hline Activity (minutes) & 202.0 & 120.5 & 7 & 389 & & $r=.72^{* *}$ \\
\hline \multicolumn{7}{|l|}{ Mean Duration } \\
\hline Activity (minutes) & 9.9 & 5.5 & 1.8 & 18.5 & & \\
\hline
\end{tabular}

total time spent in nighttime activity decreased there were fewer inactive events with increasingly longer duration.

\section{Nighttime Activity and Physiological Measures}

CSF 5-HIAA concentrations (with weight and age statistically partialled out) were inversely correlated with the frequency of active periods $(t(14)=-2.65, p<.03)$ and with the total duration of nighttime activity $(t(14)=-2.21, p<$ .05). Further analysis revealed that CSF 5-HIAA concentrations were positively correlated with the mean duration of nighttime periods of inactivity $(t(14)=2.22, p<.05)$. CSF HVA concentrations (with weight and age statistically partialled out) were inversely correlated with mean duration of nighttime activity periods $(t(14)=-4.59, p<$
.001). CSF MHPG concentrations (with Time of Day statistically partialled out) were positively correlated with mean duration of nighttime activity $(t(14)=2.56, p<.03)$.

\section{Daytime Activity and Physiological Measures}

We failed to detect any associations between daytime measures of activity and CSF 5-HIAA and HVA concentrations (age and weight statistically partialled out). In contrast, CSF MHPG concentrations (with Time of Day residualized out) were positively correlated with daytime sleep frequency $(t(14)=2.69, p<.02)$ and daytime yawning $(t(14)=2.41, p<.04)$, and inversely correlated with mean duration of activity periods $(t(14)=-2.68, p<$ .02). See Figure 1 and Figure 2.

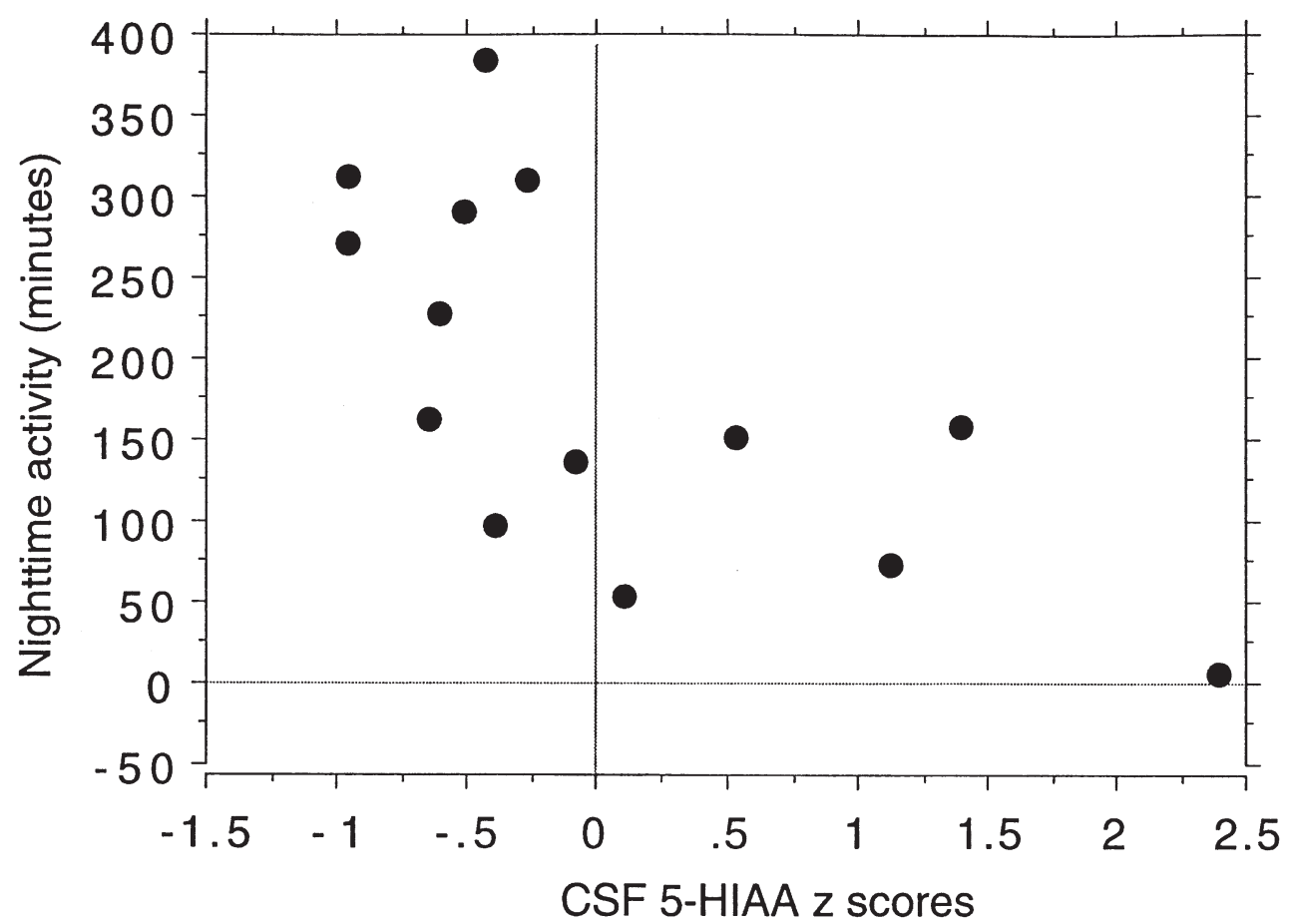

Figure 1. Scattergram plot of CSF 5-HIAA z scores (with age and weight statistically partialled out) correlated with total duration of nighttime activity in minutes. 


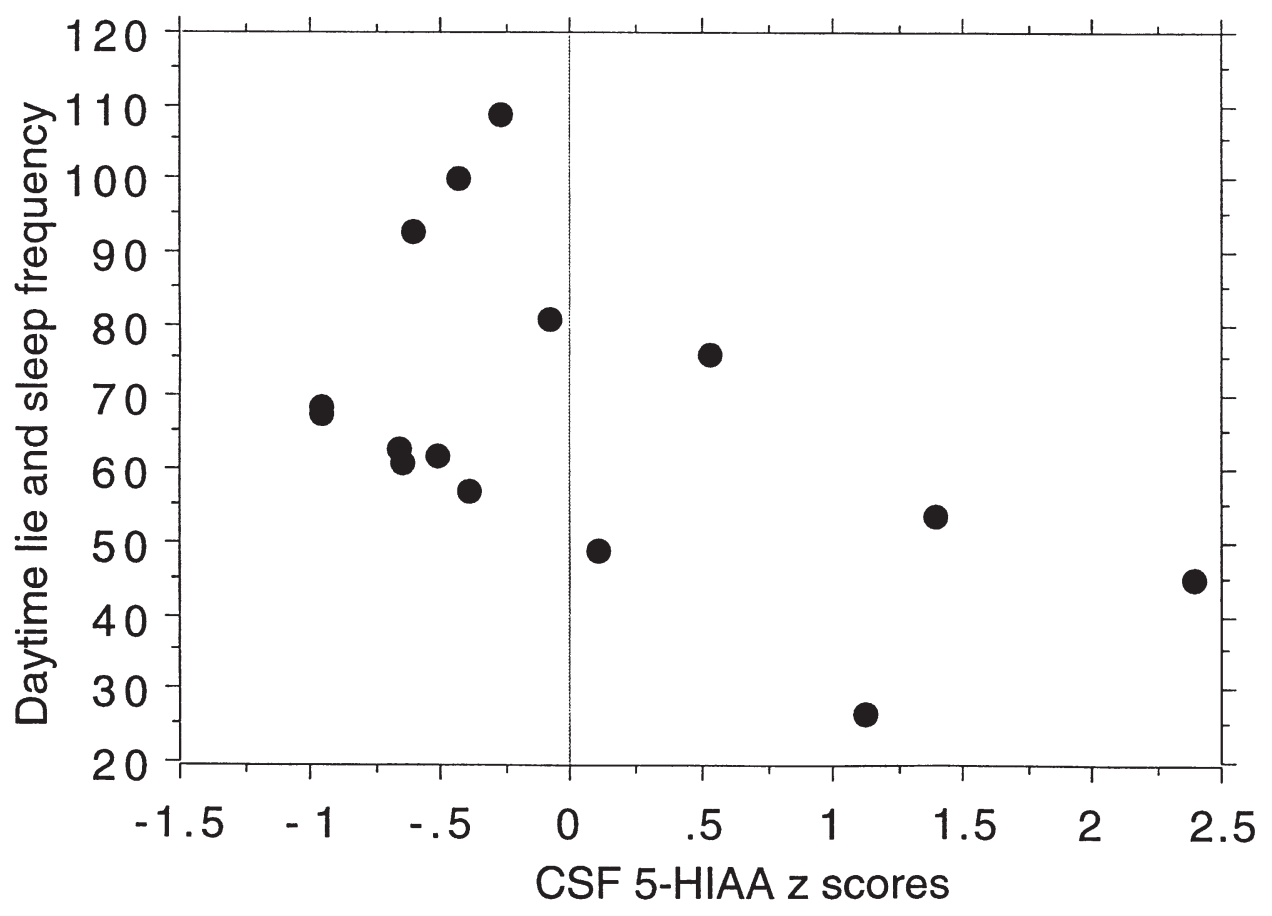

Figure 2. Scattergram plot of CSF 5-HIAA z scores (with age and weight statistically partialled out) correlated with total daytime frequency of lie and sleep combined.

\section{Daytime and Nighttime Measures of Activity}

There were no significant correlations between measures of nighttime and daytime activity. However, when extreme values of nighttime activity were removed from the distribution $(<-1.6$ or $>1.6$ standard deviations), total nighttime activity was inversely correlated with total daytime activity $(r(10)=-.63, p<.03)$. We also noted a positive correlation between nighttime activity and daytime yawning $(r(10)=.81, p<.001)$.

\section{DISCUSSION}

We found support for the primary hypothesis that time spent inactive, presumably asleep, during the nighttime hours was positively correlated with serotonin turnover rate. Similarly, subjects with low CSF 5-HIAA concentrations had higher frequencies and a higher total duration of nighttime activity than did subjects with high CSF 5-HIAA concentrations. Thus, it appears that freeranging rhesus males with low serotonergic neurotransmission are more prone to sleep difficulties such as frequent waking, high levels of nighttime activity, and possibly more tiredness during the day. These findings are consistent with research in impulsive male alcoholics with low CSF 5-HIAA concentrations showing that they exhibit aberrant diurnal activity rhythms with daytime naps, and frequent nighttime waking, and higher than normal overall daytime activity (Roy et al. 1986; Virkkunen et al. 1994). They are also consistent with a recent laboratory study of rhesus macaques showing that onset of nighttime sleep is inversely correlated with CSF 5-HIAA concentrations (Zajicek et al. 1997).

HVA and MHPG concentrations were not correlated with time spent inactive, but they were correlated with time spent active, suggesting that the catecholamines were not related to sleep, but instead associated with waking activity during the nighttime hours. This relationship between HVA and nocturnal activity remained significant even when 5-HIAA and HVA were simultaneously entered in a multiple regression analysis $(t(14)=$ $-4.48, p<.002)$. Similarly the relationship between nocturnal activity and MHPG remained significant even when 5-HIAA and MHPG were simultaneously entered in a multiple regression analysis $(t(14)=2.67$, $p<.03)$. These findings are intriguing, and suggest the possibility that the serotonin system is more strongly involved in sleep regulation, but when the subjects are awake, the serotonin and catecholamine systems are both involved in modulating activity.

We did not find an association between measures of daytime activity/inactivity and CSF 5-HIAA and HVA concentrations. This finding is of particular interest in view of research indicating that alcoholics with low CSF 5-HIAA concentrations and antisocial personality disorder (ASP) have higher than normal measures of daytime activity, while alcoholics with low CSF 5-HIAA concentrations and intermittent explosive disorder (IED) do not (Virkkunen et al. 1994). Thus, our macaque subjects appear to be more similar to patients with IED than to patients with ASP. This is consistent with the contention that increased daytime activity in ASP of- 
fenders reflects the interaction between ASP and attention deficit disorder (and its attendant hyperactivity), rather than simply lowered CSF 5-HIAA concentrations (Virkkunen et al. 1994). It must be noted that the present results are independent of previous alcohol consumption, which is known to affect peptide concentrations in the suprachiasmatic nucleus for long periods of time. To the degree that our findings generalize to the human condition, they suggest that the aberrant diurnal activity pattern seen in alcoholics with low CSF 5-HIAA concentrations is not simply a result of prolonged exposure to alcohol, but may instead be a primary behavior trait characterizing populations with impaired CNS serotonin functioning.

CSF MHPG concentrations showed a correlation pattern opposite to those of CSF 5-HIAA and HVA concentrations, exhibiting a positive correlation with nighttime activity. This is somewhat consistent with our previous studies (Higley et al. 1992b; Higley et al. 1996a) and some (Brown et al. 1979), but not with all, human studies (Virkkunen et al. 1989b) investigating alcoholism and violent behavior. In these studies, low CSF 5-HIAA and high CSF norepinephrine or MHPG concentrations were associated with violent behavior, wounding, and premature death from violent behavior. Unlike the other metabolites, MHPG exhibited correlations with daytime sleep and awake activity. Subjects with low CSF MHPG concentrations yawned and napped less, and spent more time active than did subjects with high CSF MHPG. Subsequent studies are underway to assess a more complete behavior daytime profile of subjects with low MHPG.

Jacobs, in a comprehensive reviews of CNS serotonin and diurnal activity patterns, showed that diurnal sleep-wake-arousal motor patterns are positively correlated with CNS serotonin firing patterns in many areas of the brain, including the suprachiasmatic nucleus (Jacobs 1987; Jacobs and Fornal 1998). CNS serotonin firing patterns are shown to be most active during patterns of locomotion, and least active during sleep, especially REM sleep (Jacobs 1987; Jacobs and Fornal 1998). While this seems somewhat paradoxical when considering our results (subjects with low CSF 5-HIAA concentrations were the most active, and least likely to sleep), it may be that the two different methods of measurement reflect different variables. Firing patterns of CNS serotonin neurons are phasic, specific to certain stimuli, and time-linked to motor activity or sleep patterns. CSF 5-HIAA concentration, on the other hand, is an integrated measure that has been shown to be traitlike across stimuli and situations, and while individual CSF 5-HIAA concentrations are reflective of changing states and stressors (Higley et al. 1996a; Higley et al. 1991; Higley et al. 1992b), interindividual differences are enduring. To reconcile this apparent discrepancy electrophysiological studies would need to be per- formed on subjects with high and low CSF 5-HIAA concentrations. These studies would be of considerable interest, since subjects with low CSF 5-HIAA concentrations show numerous impulse control deficits and it is possible that subjects with low CSF 5-HIAA concentrations show a less time-linked phasic link between motor patterns and CNS serotonin activity which may be related to their characteristic behavioral deficits.

This study contributes to the development of a nonhuman primate model that describes the behavioral correlates of naturally occurring variations in central serotonin turnover. In this long-term study trait-like variation in CSF 5-HIAA is correlated with an array of deleterious behavioral patterns which include severe aggression and wounding (inverse), risky, impulsive leaping (inverse), sociality (positive), early death (inverse), and sexual interactions with insemination (positive) (Higley et al. 1996b; Higley et al. 1992a; Higley et al. 1996a; Higley et al. 1996c; Joseph and Kennett 1980; Mehlman et al. 1995; Mehlman et al. 1994; Mehlman et al. 1997). The present study adds to the growing profile of behaviors associated with natural variation in CSF 5HIAA concentrations by showing an inverse correlation between central serotonin turnover rate and total nighttime activity. We conclude that male rhesus monkeys with low CSF 5-HIAA concentrations have disrupted circadian patterns, are more active at night, and less active during the day.

\section{ACKNOWLEDGMENTS}

The subjects for this research are part of a breeding colony supported by LABS of Virginia, Inc. Under Food and Drug Administration Contract 223-92-1101. LABS of Virginia, Inc. is an AAALAC accredited institution. The LABS of Virginia, Inc. Institutional Animal Care and Use Committee approved a research protocol for this study in accordance with and as required by the Animal Welfare Act. The authors wish to thank Michael Workman for collection of the nighttime activity data and Stephen Lindell, Courtney Shannon, Ted King, Scott Cheslak and the Morgan Island staff for help in physiological data collection. The authors also wish to thank Dr. Phillip Snoy (FDA) and LABS of Virginia, Inc. for authorization to conduct the research.

\section{REFERENCES}

Bacopoulos NG, Redmond DE, Roth RH (1979): Serotonin and dopamine metabolites in brain regions and cerebrospinal fluid of a primate species: Effects of ketamine and Fluphenazine. Journal of Neurochemistry 32:12151218

Brammer GL, McGuire MT, Raleigh MJ (1987): Vervet monkey (Cercopithecus aethiops sabaeus) whole blood serotonin is determined by platelet uptake sites. Life Science 41:1539-1546 
Brown GL, Goodwin FK, Ballenger JC, Goyer PF, Major LF (1979): Aggression in humans correlates with cerebrospinal fluid amine metabolites. Psychiatry Res 1:131-139

Edgar DM, Reid MS, Dement WC (1997): Serotonergic afferents mediate activity-dependent entrainment of the mouse circadian clock. Am J Physiol 273:R265-R269

Faustman WO, Faull KF, Whiteford HA, Borchert C, Csenansky JG (1990): CSF 5-HIAA, serum cortisol, and age differentially predict vegetative and cognitive symptoms in depression. Biol Psychol 27:311-318

Higley JD, King ST, Hasert MF, Champoux M, Suomi SJ, Linnoila M (1996a): Stability of interindividual differences in serotonin function and its relationship to aggressive wounding and competent social behavior in rhesus macaque females. Neuropsychopharmacology 14:67-76

Higley JD, Linnoila M, Suomi SJ (1994): Ethological contributions: Experiential and genetic contributions to the expression and inhibition of aggression in primates. Hersen M, Ammerman RT and Sisson L (eds), Handbook of Aggressive and Destructive Behavior in Psychiatric Patients. New York: Plenum Press, pp 17-32

Higley JD, Mehlman P, Taub D, Higley SB, Vickers JH, Suomi SJ, Linnoila M (1992a): Cerebrospinal fluid monoamine and adrenal correlates of aggression in free-ranging rhesus monkeys. Arch Gen Psychiatry 49:436-441

Higley JD, Mehlman PT, Higley SB, Fernald B, Vickers J, Lindell SG, Taub DM, Suomi SJ, Linnoila M (1996b): Excessive mortality in young free-ranging male nonhuman primates with low cerebrospinal fluid 5-hydroxyindoleacetic acid. Arch Gen Psychiatry 53:537-543

Higley JD, Mehlman PT, Poland RE, Taub DT, Vickers J, Suomi SJ, Linnoila M (1996c): CSF testosterone and 5HIAA correlate with different types of aggressive behaviors. Biol Psychiatry 40:1067-1082

Higley JD, Suomi SJ, Linnoila M (1991): CSF monoamine metabolite concentrations vary according to age, rearing, and sex, and are influenced by the stressor of social separation in rhesus monkeys. Psychopharmacology 103:551-556

Higley JD, Suomi SJ, Linnoila M (1992b): A longitudinal assessment of CSF monoamine metabolite and plasma cortisol concentrations in young rhesus monkeys. Biol Psychiatry 32:127-145

Jacobs BL (1987): Central monoaminergic neurons: Singleunit studies in behaving animals. Meltzer HY (eds), Psychopharmacology: The Third Generation of Progress. New York: Raven Press, pp 159-169

Jacobs BL (1991): Serotonin and behavior: Emphasis on motor control. J Clin Psychiatry 52(Supplement):17-23

Jacobs BL, Fornal CA (1998): Serotonin and behavior: A general hypothesis. American College of Neuropsychopharmacology

Joseph MH, Kennett GA (1980): Brain tryptophan and 5-HT function in stress. Br J Pharmacol 73:267

Jouvet M (1974): The role of monoaminergic neurons in the regulation and function of sleep. Basic sleep mechanisms. Petre-Quadens OS, J.D. New York, Academic Press. 207-236
Jouvet W (1967): Neurophysiology of the states of sleep. Physiology Review 47:117-177

Kaplan JR, Shively CA, Fontenot MB, Morgan TM, Howell SM, Manuck SB, Muldoon MF, Mann JJ (1994): Demonstration of an association among dietary cholesterol, central serotonergic activity, and social behavior in monkeys. Psychosom Med 56:479-484

Kennaway DJ, Rowe SA, Ferguson SA (1996): Serotonin agonists mimic the phase shifting effects of light on the melatonin rhythm in rats. Brain Res 737:301-307

Klein DC, Moore RY, Reppert SM (1991): Suprachiasmatic Nucleus: The mind's clock. New York: Oxford University Press

Koella WP (1985): Serotonin and sleep. Sleep '84. Koella WPR, EW Schultz, H Stuttgart, Gusatav Fischer Verlag. 6-9

Koella WP, Czicman JS (1966): Mechanism of the EEG synchronizing action of serotonin. Am J Physiol 211:926-934

Kruesi MJ, Rapoport JL, Hamburger S, Hibbs E, Potter WZ, Lenane M, Brown GL (1990): Cerebrospinal fluid monoamine metabolites, aggression, and impulsivity in disruptive behavior disorders of children and adolescents. Arch Gen Psychiatry 47:419-426

Lidberg L, Tuck JR, Åsberg M, Scalia-Tomba GP, Bertilsson L (1985): Homicide, suicide and CSF 5-HIAA. Acta Psychiatr Scand 71:230-236

Linnoila M, Virkkunen M, Scheinin M, Nuutila A, Rimon R, Goodwin FK (1983): Low cerebrospinal fluid 5-hydroxyindoleacetic acid concentration differentiates impulsive from nonimpulsive violent behavior. Life Sci 33:2609-2614

Maeda T, Fujimiya M, Kitahama K, Imai H, Kimura H (1989): Serotonin neurons and their physiological roles. Arch Histol Cytol 52(Supplement):113-120

Mehlman P, Higley JD, Faucher I, Lilly AA, Taub DM, Vickers JH, Suomi S, Linnoila M (1995): Correlation of CSF 5-HIAA concentration with sociality and the timing of emigration in free-ranging primates. Am J Psychiatry 152:907-913

Mehlman PT, Higley JD, Faucher I, Lilly AA, Taub DM, Suomi S, Linnoila M (1994): Low CSF 5-HIAA concentrations and severe aggression and impaired impulse control in nonhuman primates. Am J Psychiatry 151:1485-1491

Mehlman PT, Higley JD, Fernald BJ, Sallee FR, Suomi SJ, Linnoila M (1997): CSF 5-HIAA, testosterone, and sociosexual behaviors in free-ranging male rhesus macaques in the mating season. Psychiatry Res 72:89-102

Meyer-Bernstein EL, Blanchard JH, Morin LP (1997): The serotonergic projection from the raphe nucleus to the suprachiasmatic nucleus modulates activity phase onset, but not other circadian rhythm parameters. Brain Res 755:112-120

Meyer-Bernstein EL, Morin LP (1996): Differential serotonergic innervation of the suprachiasmatic nucleus and the intergeniculate leaflet and its role in circadian rhythm modulation. J Neurosci 16:2097-2111

Miller JD, Morin LP, Schwartz WJ, Moore RY (1996): New insights into the mammalian circadian clock. Sleep 19:641-667 
Possidente B, Lumia AR, McGinnis MY, Rapp M, McEldowney S (1996): Effects of fluoxetine and olfactory bulbectomy on mouse circadian activity rhythms. Brain Res 713:108-113

Prosser RA, Dean RR, Edgar DM, Heller HC, Miller JD (1993): Serotonin and the mammalian circadian system. I. In vitro phase shifts by serotonin agonists and antagonists. Journal of Biological Rhythms 1-16

Puizillout JJ, Gaudin CG, Sayadi A, Vigier D (1981): Serotoninergic mechanisms and sleep. Journal of Physiology (Paris) 77:415-424

Raleigh MJ (1987): Differential behavioral effects of tryptophan and 5-hydroxytryptophan in vervet monkeys: Influence of catecholaminergic systems. Psychopharmacology 93:44-50

Raleigh MJ, Brammer GL, McGuire MT (1983a): Male dominance, serotonergic systems, and the behavioral and physiological effects of drugs in vervet monkeys (Cercopithecus aethiops sabaeus). Miczek KA (eds), Ethopharmacology: Primate Models of Neuropsychiatric Disorders. New York: Alan R. Liss, pp 185-197

Raleigh MJ, Brammer GL, McGuire MT, Yuwiler A, Geller E, Johnson CK (1983b): Social status related differences in the behavioral effect of drugs in vervet monkeys (Cercopithecus aethiops sabaeus). Steklis HD and Kling AS (eds), Hormones, Drugs \& Social Behavior in Primates. New York: SP Medical \& Scientific Books, pp 83-105

Raleigh MJ, Brammer GL, Yuwiler A, Flannery JW, McGuire MT (1980): Serotonergic influences on the social behavior of vervet monkeys (Cercopithecus aethiops sabaeus). Exp Neurol 68:322-334

Raleigh MJ, McGuire MT (1994): Serotonin, aggression, and violence in vervet monkeys. Masters RD and McGuire MT (eds), The Neurotransmitter Revolution. Carbondale: Southern Illinois University Press, pp 129-145

Roy A, Virkkunen M, Guthrie S, Linnoila M (1986): Indices of serotonin and glucose metabolism in violent offenders, arsonists, and alcoholics. Ann N Y Acad Sci 487:202-220

Scheinin M, Chang WH, Jimerson DC, Linnoila M (1983): Measurement of 3-methoxy-4-hydroxyphenylglycol in human plasma with high-performance liquid chromatography using electrochemical detection. Anal Biochem 132:165-170

Selim M, Glass JD, Hauser UE, Rea MA (1993): Serotonin inhibition of light-induced foc protein expression and extracellular glutamate in the suprachiasmatic nuclei. Brain Res 621:181-188

Smale L, Michels KM, Moore RY, Morin LP (1990): Destruction of the hamster serotonergic system by 5,7-DHT: effects on circadian rhythm phase, entrainment, and response tp traizolem. Brain Res 515:9-19

Taub DM, Mehlman PT (1989): Development of the Morgan Island Rhesus Monkey colony. PRHSJ 8:159-169

Torda C (1967): Effect of brain serotonin depletion on sleep in rats. Brain Res 6:375-377

Virkkunen M, De Jong J, Bartko J, Goodwin FK, Linnoila M (1989a): Relationship of psychobiological variables to recidivism in violent offenders and impulsive fire setters. A follow-up study. Arch Gen Psychiatry 46:600-603

Virkkunen M, De Jong J, Bartko J, Linnoila M (1989b): Psychobiological concomitants of history of suicide attempts among violent offenders and impulsive fire setters. Arch Gen Psychiatry 46:604-606

Virkkunen M, Narvanen S (1987): Plasma insulin, tryptophan and serotonin levels during the glucose tolerance test among habitually violent and impulsive offenders. Neuropsychobiol 17:19-23

Virkkunen M, Rawlings R, Tokola R, Poland RD, Guidotti A, Nemeroff C, Bissette G, Kalogeras K, Karonen SL, Linnoila M (1994): CSF biochemistries, glucose metabolism, and diurnal activity rhythms in alcoholic, violent offenders, fire setters, and healthy volunteers. Arch Gen Psychiatry 51:20-27

Weitzman ED, Rapport MM, McGregor P, Jacoby J (1968): Sleep patterns of the monkey and brain serotonin concentration: Effect of p-chlorophenylalanine. Science 160:1361-1363

Zajicek K, Higley JD, Suomi SJ, Linnoila M (1997): Rhesus macaques with high CSF 5-HIAA concentrations exhibit early sleep onset. Psychiatry Res 73:15-25 